\title{
Robustness Metrics: Consolidating the multiple approaches to quantify Robustness
}

\author{
Göhler, Simon Moritz; Eifler, Tobias; Howard, Thomas J.
}

Published in:

Journal of Mechanical Design

Link to article, DOI:

$10.1115 / 1.4034112$

Publication date:

2016

Document Version

Peer reviewed version

Link back to DTU Orbit

Citation (APA):

Göhler, S. M., Eifler, T., \& Howard, T. J. (2016). Robustness Metrics: Consolidating the multiple approaches to quantify Robustness. Journal of Mechanical Design, 138, [111407]. https://doi.org/10.1115/1.4034112

\section{General rights}

Copyright and moral rights for the publications made accessible in the public portal are retained by the authors and/or other copyright owners and it is a condition of accessing publications that users recognise and abide by the legal requirements associated with these rights.

- Users may download and print one copy of any publication from the public portal for the purpose of private study or research.

- You may not further distribute the material or use it for any profit-making activity or commercial gain

- You may freely distribute the URL identifying the publication in the public portal

If you believe that this document breaches copyright please contact us providing details, and we will remove access to the work immediately and investigate your claim. 
ASME Journal of Mechanical Design Intended for the special issue on "Simulation-based Design under Uncertainty."

\title{
Robustness Metrics: Consolidating the multiple approaches to quantify Robustness
}

\author{
MD-16-1166 (Research paper)
}

\author{
Göhler, Simon Moritz ${ }^{1}$ \\ Technical University of Denmark \\ Produktionstorvet, Building 426 \\ 2800 Kgs. Lyngby \\ Denmark \\ simogo@mek.dtu.dk
}

\section{Eifler, Tobias}

Technical University of Denmark Produktionstorvet, Building 426 2800 Kgs. Lyngby

Denmark

tobeif@mek.dtu.dk

Howard, Thomas J.

Technical University of Denmark Produktionstorvet, Building 426 2800 Kgs. Lyngby

Denmark thow@mek.dtu.dk

\footnotetext{
${ }^{1}$ Corresponding author.
} 
ASME Journal of Mechanical Design

\section{ABSTRACT}

The robustness of a design has a major influence on how much the product's performance will vary and is of great concern to design, quality and production engineers. While variability is always central to the definition of robustness, the concept does contain ambiguity and although subtle, this ambiguity can have significant influence on the strategies used to combat variability, the way it is quantified and ultimately, the quality of the final design. In this contribution the literature for robustness metrics was systematically reviewed. From the 108 relevant publications found, 38 metrics were determined to be conceptually different from one another. The metrics were classified by their meaning and interpretation based on the types of information necessary to calculate the metrics. Four different classes were identified: 1) Sensitivity robustness metrics; 2) Size of feasible design space robustness metrics; 3) Functional expectancy and dispersion robustness metrics; and 4) Probability of compliance robustness metrics. The goal was to give a comprehensive overview of robustness metrics and guidance to scholars and practitioners to understand the different types of robustness metrics and to remove the ambiguities of the term robustness. By applying an exemplar metric from each class to a case study, the differences between the classes were further highlighted. These classes form the basis for the definition of four specific sub-definitions of robustness, namely the 'robust concept', 'robust design', 'robust function' and 'robust product'.

Keywords: Robust Design, Robustness, Sensitivity, Metric, Classification, Review

Corresponding author: Göhler, Simon Moritz MD-16-1166 (Research paper) 2 of 42 
ASME Journal of Mechanical Design

\section{INTRODUCTION}

There is much need to clarify the term robustness. While robustness is a property of a design or product that is considered of great importance in many industries, the terms robustness will seldom appear in a requirement specification, partly due to its ambiguity, confusion and misrepresentation. The term has a completely different meaning in common parlance, where consumers will often consider it to be synonymous with strength or durability. In this article we seek to remove the ambiguity surrounding the technical interpretation of robustness, which is broadly considered by engineers as a property that reduces variability. 'Robust Design' [verb] is therefore a methodology for designing products, devices and production equipment to perform as intended despite variation in manufacturing, assembly, material properties, ambient conditions, loading scenarios or time related factors [1]-[3]. Unlike the majority of design and analysis techniques that are based on nominal values [1], Robust Design provides an economical approach to address product quality in complement to the control of manufacturing performance by means of production-focused quality initiatives, such as Total Quality Management (TQM), Lean Manufacturing or Six Sigma.

While the basic paradigm and the fundamental benefits of Robust Design are widely accepted by scholars and practitioners, the implementation of a consistent Robust Design strategy is cumbersome for many organizations [4]-[6]. Robust Design is a very tool/method centric discipline with vaguely a defined robust design process [7], and as a consequence only experts know what to apply and when. Furthermore, the term Robustness is frequently used almost interchangeably with Sensitivity in a wide 
ASME Journal of Mechanical Design

range of related, but not clearly delimited research areas, such as sensitivity analysis, computational model building, optimization etc. [8]-[10].

A reason for the lack of coherence in terminology is perhaps due to the broad range of Robust Design activities, from systematic identification of key characteristics [11] through benchmark and comparison of products and processes [2], [12], [13] to the optimization of robustness and computer-aided tolerancing [8]. Such activities require metrics and indicators that typically differ to suit the activity and are frequently not straight forward to interpret. Previous reviews of robustness optimization techniques indirectly discuss different robustness metrics, however, without reflecting on the different implications of the choice of specific metrics for optimization [8], [14]-[16].

To foster a better understanding of the wide range of available approaches to quantify robustness, this research addresses the ambiguity surrounding the term robustness. The goal of this review is to classify robustness metrics based on their meaning and interpretation.

The remainder of this article is organized as follows. The search criteria and review process for the systematic literature review is described in section 2 . In order to organize the metrics uncovered, a theoretical framework is proposed underpinned by the information entities relevant to the basic Robust Design paradigm in Section 3. The unique robustness metrics are then classified and analyzed in Section 4 and exemplar metrics from each class are described and applied to a case example to illustrate the differences. In section 5, the verification and validity of the classification scheme as well as the interpretation of the different classes with respect to different facets of 
ASME Journal of Mechanical Design

robustness are discussed, before concluding the results and the potential of this research in section 6 .

\section{SYSTEMATIC LITERATURE REVIEW PROCESS}

The quantification of parameter sensitivities plays a large role in almost all scientific fields that use models to describe, analyze and predict phenomena and synthesize products and systems. As a result, there exist a very large number of scientific manuscripts on sensitivity analysis and metrics with focus on special application scenarios. However, the concept of robustness is not entirely congruent with that of sensitivity. Since these terms of are often used as antonyms of one another, a thorough review of the related metrics may help with clarifying the distinction between the terms.

For this purpose a systematic literature review [17] was conducted to create a comprehensive collection of robustness and sensitivity metrics that can be used in the realm of Robust Design. The objective of this extraction was to collect as many fundamentally different metrics as possible. Throughout this article the term metric will be used and is unless otherwise stated referring to a measure or quantification of the robustness of a design or product. A review protocol was established prior to the study to ensure a rigorous execution [17].

To establish a general understanding of robustness and sensitivity metrics, 6 primary publications were reviewed covering sensitivity analysis in general terms [9], [10], [18] and focused on sampling-based methods [19] as well as sensitivity indices 
ASME Journal of Mechanical Design

particularly for the use in Robust Design [13], [20] . Based on this initial review the relevant keywords and search strings for the study were defined as follows:

- Robust Design, Robust Engineering, Robustness to variation, Design for robustness, Robust product design, Taguchi, Sensitivity to variation, Insensitivity to variation, Sensitive to variation, Insensitive to variation, Functional Variation

AND

- Indicator, Indicator" OR "Quantifier" OR "Metric" OR "sensitivity measure" OR "Index" OR "Indices" OR "Sensitivity Information" OR "score"

To include potential metrics outside of the field of robust design but yet applicable for this purpose a second search for reviews of sensitivity analysis methods in general has been conducted. As sources, the databases of Scopus and ISI Web of Science were selected due to their comprehensive collection of scientific articles relevant to this research. The search was limited to peer-reviewed journal articles to ensure a high level of quality. Furthermore, only publications in the English language and in the field of engineering were considered. The inclusion criteria were the proposal, application or review of robustness metrics to evaluate the robustness/sensitivity to variation. Excluded were studies on robustness optimization and process capabilities that did NOT specifically describe novel ways and ideas to describe robustness.

For each of the different robustness metrics the mathematical description was taken from the article in order to gain a true understanding of the metric which was less Corresponding author: Göhler, Simon Moritz MD-16-1166 (Research paper) 6 of 42 
ASME Journal of Mechanical Design

reliant on the authors' terminology or explanation. Overall, the terminology used in the literature is very inconsistent. Every metric was only recorded once by discarding duplicates and minor variations of a metric. A minor variation of a metric would be one which only differs from another metric in the way the normalizing or averaging is conducted for example. Table 1 shows the extraction statistics of the systematic literature review. At the end of the selection process 90 relevant articles were identified. The list of references also includes 18 additional references that were identified during reading for extensions and clarification of metrics. The review revealed 38 different metrics for robustness (Table 5 in the appendix).

Table 1: Extraction statistic of the systematic literature review

\begin{tabular}{|c|c|c|c|c|}
\hline Database & \multicolumn{2}{|c|}{ Scopus } & \multicolumn{2}{c|}{ ISI Web of Science } \\
\hline Search Strings & $\begin{array}{c}\text { Robust Design* } \\
+ \text { Indicators* }\end{array}$ & $\begin{array}{c}\text { "Sensitivity } \\
\text { Analysis } \\
\text { methods" } \\
\text { Review }\end{array}$ & $\begin{array}{c}\text { Robust Design* } \\
+ \text { Indicators* }\end{array}$ & $\begin{array}{c}\text { "Sensitivity } \\
\text { Analysis } \\
\text { methods" + } \\
\text { Review }\end{array}$ \\
\hline Total hits & 252 & 38 & 418 & 34 \\
\hline Extracted & 55 & 16 & 36 & 12 \\
\hline \multicolumn{4}{|c|}{90 (Scopus/ISI WoS) + 18 (additional sources) } \\
\hline Total unique \\
references
\end{tabular}

\section{THEORETICAL FRAMEWORK}

While robustness metrics have a very broad range of applications in all areas, in this article the review is conducted in the context of product development and engineering design. The classic categorization of Robust Design methods and metrics has been done differentiating between different types and sources of uncertainties.

Corresponding author: Göhler, Simon Moritz MD-16-1166 (Research paper) 7 of 42 
ASME Journal of Mechanical Design

Historically there is a distinction made between type I and type II Robust Design addressing variations in noise factors (uncontrollable) and design parameters (controllable) respectively [21]. A third type was introduced later by Allen et al. [22] to include variability and uncertainty in the system models. A fourth type was mentioned by Beyer and Sendhof [8] addressing the "uncertainties concerning the fulfillment of constraints the design variables must obey". These uncertainties can further be categorized being deterministic, probabilistic (aleatory) or possibilistic (epistemic) in nature [8]. Aleatory uncertainty is the 'stochastic intrinsic variability associated with a physical system or environment'. The epistemic uncertainty is related to incomplete knowledge [23].

In this study, the transfer function model (TFM), as described in Robust Design Methodology, was selected as a basis for the analysis of the metrics. The TFM is a means to relate design parameters (and noise factors) to the functional performance and is used effectively to promote good design practice in Axiomatic Design [24] and the Variation Management Framework [25].

Corresponding author: Göhler, Simon Moritz $\quad$ MD-16-1166 (Research paper) 8 of 42 


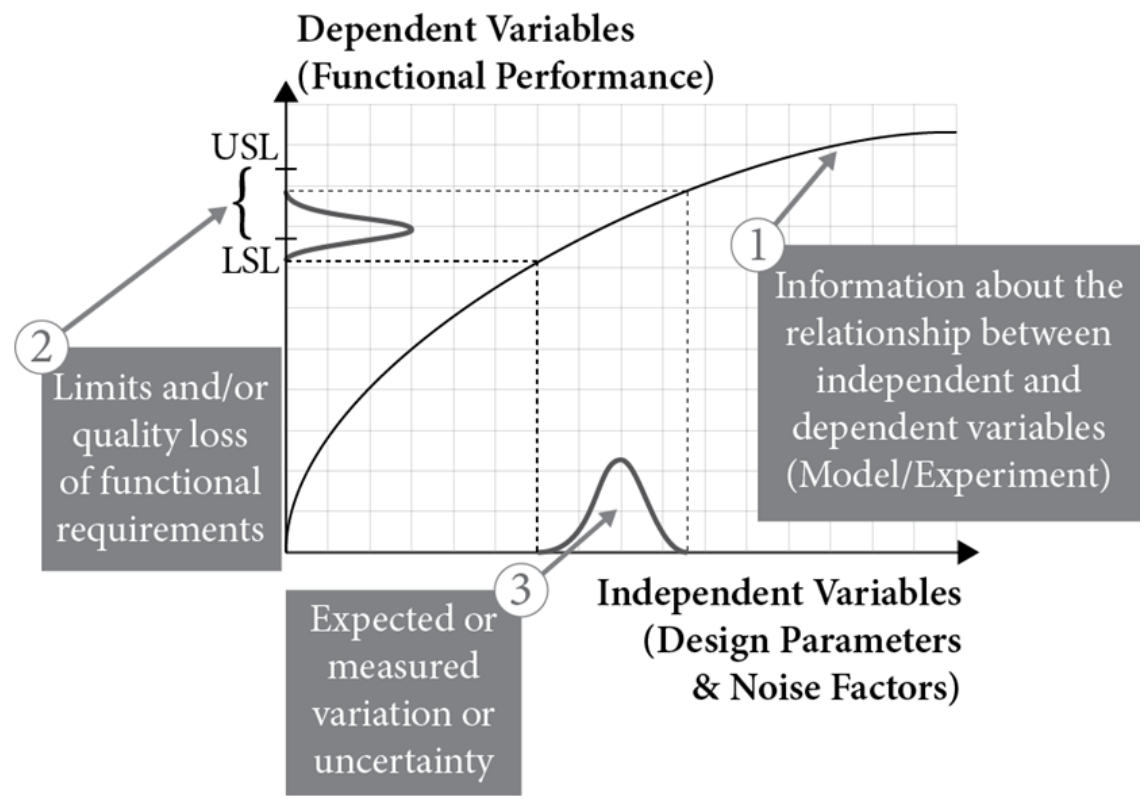

Figure 1: Robust Design framework

Figure 1 shows the classical representation of describing the propagation of variation from the physical domain to the functional domain. The different entities are:

1. A model or an experiment. When using a model, the relations within the process need to be understood in order to calculate the robustness, whereas using an experiment treats the process as a black box taking just inputs and output to calculate sensitivities.

2. Functional specification limits or quality loss characteristics defined by the voice of the customer and the business unit's profile for the product.

3. Quantified ingoing variation or uncertainty, such as design parameter variation, capability data and variation in use case or noise described in the mission profile (deterministic or probabilistic). The incorporation of epistemic uncertainty bears further challenges to uncertainty modeling 
ASME Journal of Mechanical Design

utilizing for example fuzzy sets [26], [27] and is considered out of scope for this review.

To analyze the robustness metrics their mathematical descriptions were reviewed with respect to which of the information entities they process (Figure 1 ) and what meaning and interpretation of the metrics follow from the TFM.

While the TFM, as seen in Figure 1, only relates one design parameter to one functional requirement, it was important to also consider complexity in the analysis, i.e. are single or multiple design parameters correlated to single or multiple functional requirements. However, it has to be noted that metrics that are used to take the average, maximum or minimum of other robustness metrics are not included in the review. The objective analysis of the mathematical descriptions ensured the reliability of the coding for the classification scheme avoiding any ambiguity in classifying the metrics.

The generic scheme for the analysis of the robustness metrics is summarized in Table 2. The results of the analysis of the 38 different metrics identified in the literature review can be found in Table 5 in the appendix. The findings are complete with respect to the searched databases and generally comprehensive from the authors' point of view.

Corresponding author: Göhler, Simon Moritz MD-16-1166 (Research paper) 10 of 42 
ASME Journal of Mechanical Design

Table 2: Analysis scheme for robustness metrics

\begin{tabular}{|c|c|c|c|c|c|c|c|c|}
\hline \multirow[b]{2}{*}{ \# } & \multirow[b]{2}{*}{ Name } & \multirow[b]{2}{*}{$\begin{array}{c}\text { Mathematical } \\
\text { Expression }\end{array}$} & \multicolumn{3}{|c|}{ Necessary information Entities } & \multicolumn{2}{|c|}{ Level of complexity } & \\
\hline & & & $\begin{array}{c}\text { Model / } \\
\text { Experiment }\end{array}$ & $\begin{array}{l}\text { Functional } \\
\text { Limits }\end{array}$ & $\begin{array}{l}\text { Expected } \\
\quad / \\
\text { measured } \\
\text { variation }\end{array}$ & $\begin{array}{c}\text { Independent } \\
\text { variables } \\
\text { (DPs + NFs) } \\
\text { single / } \\
\text { multiple }\end{array}$ & $\begin{array}{c}\text { Dependent } \\
\text { variables } \\
\text { (Functional } \\
\text { performance) } \\
\text { single / } \\
\text { multiple }\end{array}$ & Ref. \\
\hline & & & & & & & & \\
\hline
\end{tabular}

\section{CATEGORIZATION OF ROBUSTNESS METRICS}

The aim of this study is NOT to review and describe each and every metric in depth, since full details of the metrics can be found in the individual references provided. The goal of this study is rather to take a step back to give a classification of a comprehensive collection of robustness metrics in order to address the overall ambiguities of the term robustness and the selection of appropriate metrics as described in the opening of this paper.

Based on the analysis of the metrics (full table of results in the APPENDIX Table 5), the following classification scheme was derived (Table 3). All of the 38 reviewed robustness metrics could be classified into one of four different classes.

1. Sensitivity robustness metrics that quantify the influence of one or more design parameters or noise factors (independent factors) to the functional output (see section 4.1).

2. Metrics that describe the size of the feasible design space as measure for the robustness (see section 4.2).

Corresponding author: Göhler, Simon Moritz MD-16-1166 (Research paper) 11 of 42 
ASME Journal of Mechanical Design

3. Metrics that evaluate different expectancy and dispersion measures of the functional output (see section 4.3).

4. Metrics that evaluate the probability of functional compliance meaning that all functions are satisfactory fulfilled under the influence of ingoing variation (see section 4.4).

Table 3: Classification scheme for robustness metrics

\begin{tabular}{|c|c|c|c|c|c|}
\hline \multicolumn{2}{|c|}{ Robustness Metric Class } & $\begin{array}{c}\text { Sensitivity } \\
4.1\end{array}$ & $\begin{array}{c}\text { Size of } \\
\text { feasible } \\
\text { design space } \\
4.2\end{array}$ & $\begin{array}{c}\text { Functional } \\
\text { expectancy } \\
\text { and } \\
\text { dispersion } \\
4.3\end{array}$ & $\begin{array}{c}\text { Probability } \\
\text { of functional } \\
\text { compliance } \\
4.4\end{array}$ \\
\hline \multicolumn{2}{|c|}{ Meaning in the TFM } & & & & \\
\hline \multirow{3}{*}{$\begin{array}{c}\text { Necessary } \\
\text { information } \\
\text { entities }\end{array}$} & $\begin{array}{c}\text { Model / } \\
\text { Experiment }\end{array}$ & $\checkmark$ & $\checkmark$ & $\checkmark$ & $\checkmark$ \\
\hline & $\begin{array}{l}\text { Functional } \\
\text { limits }\end{array}$ & - & $\checkmark$ & - & $\checkmark$ \\
\hline & $\begin{array}{c}\text { Expected / } \\
\text { measured } \\
\text { variation } \\
\end{array}$ & - & - & $\checkmark$ & $\checkmark$ \\
\hline \multirow{3}{*}{$\begin{array}{c}\text { Level of } \\
\text { complexity } \\
\text { (\# of } \\
\text { functions / \# } \\
\text { of } \\
\text { independent } \\
\text { variables) } \\
\end{array}$} & $1 / 1$ & $\checkmark$ & $\checkmark$ & $\checkmark$ & $\checkmark$ \\
\hline & $1 / n$ & $(\sqrt{ })$ & $\checkmark$ & $\checkmark$ & $\checkmark$ \\
\hline & $n / n$ & - & $\checkmark$ & $\checkmark$ & $\checkmark$ \\
\hline
\end{tabular}

Within each class, the metrics were further analyzed in terms of the level complexity they address:

- Robustness of a single function to a single independent variable.

Corresponding author: Göhler, Simon Moritz MD-16-1166 (Research paper) 12 of 42 
ASME Journal of Mechanical Design

- Robustness of a single function to sets of independent variables with interactions

- Robustness of a system of functions with coupling

The different classes will be explained in the following including the application of one robustness metric of each class on the example of the Toyota gas pedal case.

\section{Example - Toyota Gas Pedal}

One of most extensive recalls in automotive history occurred in 2009/10 when the car manufacturer Toyota had to recall several million cars due to an overly sensitive gas pedal which in some instances failed to return after being pressed causing the vehicle to continually accelerate, resulting in numerous serious accidents and fatalities [28]. The mechanism of the gas pedal is supposed to limit the torque required by the driver to hold the pedal in a constant position. This function is realized by a rocker that creates a friction on the pedal head to damp the return moment driven by a spring mounted between the other side of the rocker and the pedal. A simplified description of the problem (Figure 2) will be used as an example to show the differences between the different classes of robustness metrics.

The return moment $M$ is a function of the dimensions $a, b, c, d, s$, the coefficient of friction $\mu_{f}$, the spring constant $k$ and can be derived using the balance of forces and moments. This gives following simplified expression for the return moment:

Corresponding author: Göhler, Simon Moritz MD-16-1166 (Research paper) 13 of 42 
ASME Journal of Mechanical Design

$$
M=F_{\text {spring }} \cdot\left(b-\frac{c}{d} \cdot \mu_{f} \cdot a\right) \text { with } F_{\text {spring }}=k \cdot s
$$

$M$ always needs to be greater than zero to ensure a release of the throttle and below $500 \mathrm{Nmm}$ to limit the effort for the driver to push the throttle. A second functional requirement shall be the integrity of the friction shoe (red part), where the bending stress $\sigma_{b}$ needs to be below the material's yield stress $\sigma_{\max }$ at all times to prevent a failure. A simplified analytical expression for the bending stress can be written as follows where $w$ and $h$ are the width and the height of the friction shoe respectively:

$$
\sigma_{b}=\frac{6 \cdot F_{\text {spring }} \cdot c}{w \cdot h^{2}}
$$
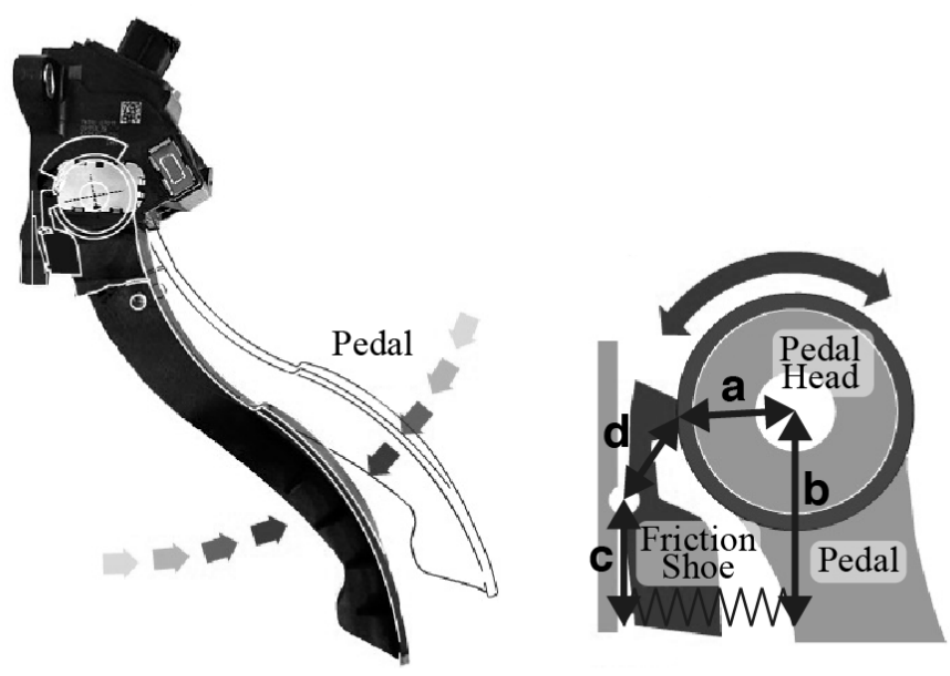

Figure 2: Schematic diagram of the Toyota gas pedal [28]

Table 4 summarizes the nominal dimensions and the expected (manufacturing) variation. Note that while the model for the mechanism is an accurate description, the limits and dimensions have been fabricated for example purposes. 
ASME Journal of Mechanical Design

Table 4: Nominal dimensions and material properties and variation data for the Toyota gas pedal input parameters

\begin{tabular}{|l|l|l|l|}
\hline & Nominal & $\begin{array}{l}\text { Estimated } \\
\text { Variation (+/-) }\end{array}$ & $\begin{array}{l}\text { Probability } \\
\text { distribution }\end{array}$ \\
\hline$a$ & $10 \mathrm{~mm}$ & $0.04 \mathrm{~mm}$ & Normal \\
\hline$b$ & $16 \mathrm{~mm}$ & $0.0483 \mathrm{~mm}$ & Normal \\
\hline$c$ & $10 \mathrm{~mm}$ & $0.04 \mathrm{~mm}$ & Normal \\
\hline$d$ & $6 \mathrm{~mm}$ & $0.035 \mathrm{~mm}$ & Normal \\
\hline$k$ & $4 \mathrm{~N} / \mathrm{mm}$ & $1 \mathrm{~N} / \mathrm{mm}$ & Uniform \\
\hline$s$ & $16 \mathrm{~mm}$ & $0.1 \mathrm{~mm}$ & Normal \\
\hline$\mu_{f}$ & 0.7 & 0.5 & Uniform \\
\hline$w$ & $4 \mathrm{~mm}$ & $0.03 \mathrm{~mm}$ & Normal \\
\hline$h$ & $5 \mathrm{~mm}$ & $0.032 \mathrm{~mm}$ & Normal \\
\hline$\sigma_{\max }$ & $50 \mathrm{MPa}$ & $5 \mathrm{MPa}$ & Normal \\
\hline
\end{tabular}

\subsection{Sensitivity robustness metrics}

Sensitivity measures play an important role in model building and corroboration as well as parameter prioritization [9]. They also build the simplest form of robustness metric and are a well-established way to relate the change of an independent variable to the change of a dependent variable. In the context of engineering design this relates to the correlation between design parameters or noise factors as independent/input variables to the functional requirements (dependent/ output variables). The metrics are based on the evaluation of finite quotients of the form:

$$
\frac{f\left(x_{1}\right)-f\left(x_{2}\right)}{x_{1}-x_{2}} \text { or } \frac{f(x+\Delta)-f(x)}{\Delta}
$$

For the limit of the interval $\Delta \rightarrow 0$ the latter expression yields the formal definition of the derivative of a function $f$ towards a variable $x$ (Equ. 4). In the case of multiple independent variables it becomes the partial derivative (Equ. 5)

Corresponding author: Göhler, Simon Moritz MD-16-1166 (Research paper) 15 of 42 
ASME Journal of Mechanical Design

$$
\begin{gathered}
\mathrm{f}^{\prime}(\mathrm{x})=\lim _{\Delta \rightarrow 0} \frac{f(x+\Delta)-f(x)}{\Delta} \\
\frac{\partial f(X)}{\partial x_{i}}=\lim _{\Delta \rightarrow 0} \frac{f\left(x_{1}, \ldots, x_{i}+\Delta, \ldots, x_{n}\right)-f(X)}{\Delta}
\end{gathered}
$$

The robustness metrics in this class are either point or range based, which induces certain assumptions and limitations that shall not be further discussed here. There are numerous ways to normalize the metrics to make the measures comparable between different functions and variables.

A simple example for this category is the Nominal-range sensitivity (NRS) metric. For the gas pedal example introduced earlier the metric yields 2.6 for the dimension $d$ with a $5 \%$ variation interval (Equ. 6).

$$
\mathrm{NRS}_{\mathrm{d}}=\frac{\frac{k \cdot s \cdot\left(b-\frac{c}{d \cdot(1+0.05)} \cdot \mu \cdot a\right)}{\mathrm{M}_{\text {nominal }}}-1}{0.05} \approx 2.6
$$

The Nominal range sensitivity describes the amplifying or damping effect of a parameter towards a function. In this case, a variation in the dimension $d$ leads to a relative change in the return moment that is $\sim 2.6$ times larger than the ingoing variation for $d$.

Sensitivity robustness metrics are independent of accurate (realistic) information about variation in the independent variables (information entity 3 Figure 1). However, range based metrics require bounds for the evaluation which are in some cases taken from the expected variation but don't have to be. Also, no information about requirements (functional limits) is necessary (information entity 2 Figure 1 ). 
ASME Journal of Mechanical Design

Sensitivity robustness metrics usually evaluate the robustness of one function with respect to one independent variable (DP or noise factor). The coefficients in linear regression modelling which belong to this class of robustness metrics can (in a limited fashion) however also be derived for interaction effects with multiple independent variables. There are no metrics in this category addressing multiple functions other than taking the minimum, maximum or any kind of average neglecting interaction effects.

Summary:

\begin{tabular}{|c|c|c|c|c|c|}
\hline \multicolumn{2}{|c|}{ Necessary information entities } & \multicolumn{2}{c|}{$\begin{array}{r}\text { Level of complexity (\# of functions / \# of } \\
\text { independent Variables) }\end{array}$} \\
\hline $\begin{array}{c}\text { Model/ } \\
\text { Experiment }\end{array}$ & $\begin{array}{c}\text { Functional } \\
\text { limits }\end{array}$ & $\begin{array}{c}\text { Expected / } \\
\text { measured } \\
\text { variation }\end{array}$ & $1 / 1$ & $1 / \mathrm{n}$ & $\mathrm{n} / \mathrm{n}$ \\
\hline$\checkmark$ & - & - & $\checkmark$ & $(\checkmark)$ & - \\
\hline
\end{tabular}

\subsection{Size of feasible design space robustness metrics}

This class of robustness metrics is based upon the evaluation of the size of the feasible design space. The metrics require in addition to information about the relationship between independent and dependent variables (information entity (1)), the functional limits (information entity (2)). They therefore put sensitivities into perspective to the requirements on the associated function. Functions can be extremely sensitive when evaluating robustness using the measures presented in 4.1 but yet could be robust in the sense that the requirements on the associated function are rather loose.

Two principles are behind the robustness metrics in this class. The first addresses the question of how much variation (across all independent variables) can be allowed 
ASME Journal of Mechanical Design

ensuring that the function will always be within the limits, i.e. what is the closest 'distance' to the most constraining limit?

The second principle is measuring the entire feasible design space as a metric for robustness. This relates to a distance, area, volume and polyhedron volume in 1D, 2D, $3 \mathrm{D}$ and $\mathrm{nD}$ respectively. The first principle is dependent on the nominal configuration and reflects a pessimistic approach; the latter is independent of the nominal and reflects an averaging approach to measure robustness. Size of feasible design space robustness measures are generally independent of information about the variation in the ingoing parameters. However, metrics like the Mahalanobis distance [29] use variancecovariance matrices to also address the likelihood of violating a constraint. In that case the distance is scaled with the magnitude of the variance and covariance.

In the one-dimensional case that the size of the feasible design space is to be derived for one independent variable $x$ towards one functional requirement $f(x)$ with an upper and lower specification limit, the calculation reduces to the trivial expressions:

1) Robustness radius:

$r_{R}=\min \left(\left|\left(x \mid f(x)=f_{\text {max }}\right)-x_{\text {nominal }}\right| ;\left|\left(x \mid f(x)=f_{\text {min }}\right)-x_{\text {nominal }}\right|\right)$

2) Feasible space:

$$
\text { Vol }=\left|\left(x \mid f(x)=f_{\text {max }}\right)-\left(x \mid f(x)=f_{\text {min }}\right)\right|
$$

Figure 3 visualizes the difference between the two concepts of robustness measures in this class. On the one hand the distance from the nominal to the closest constraint and the other hand the total feasible design space is shown. 
ASME Journal of Mechanical Design

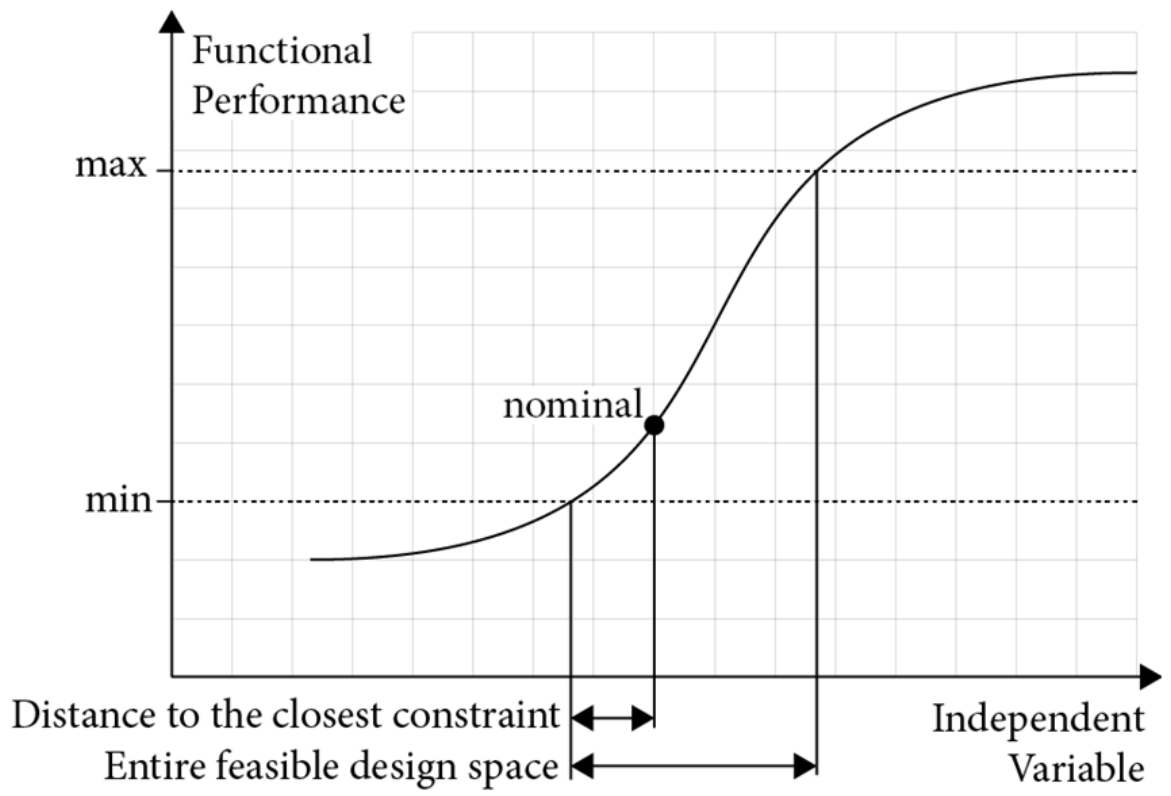

Figure 3: Size of feasible design space robustness measure (1D)

In the 1D case with the independent variable being a design parameter, this

metric can directly be compared to the associated production capabilities to determine the expected yield. Interactions and additive effects are not considered. The metrics can be used to compare the influences of independent variables on the function.

For the example of the Toyota gas pedal and its return moment the size of the feasible design space of the dimension $d$ neglecting interaction and additive effects is:

$$
\begin{gathered}
r_{R_{d}}=\min \left(\left|\left(d \mid f(d)=f_{\text {max }}\right)-x_{\text {nominal }}\right| ;\left|\left(d \mid f(d)=f_{\text {min }}\right)-x_{\text {nominal }}\right|\right) \\
=\min (|8.55 \mathrm{~mm}-6 \mathrm{~mm}| ;|4.375 \mathrm{~mm}-6 \mathrm{~mm}|)=1.625 \mathrm{~mm} \\
V o l_{d}=\left|\left(x \mid f(x)=f_{\text {max }}\right)-\left(x \mid f(x)=f_{\text {min }}\right)\right|=8.55 \mathrm{~mm}-4.375 \mathrm{~mm} \\
=4.175 \mathrm{~mm}
\end{gathered}
$$

Corresponding author: Göhler, Simon Moritz MD-16-1166 (Research paper) 19 of 42 
ASME Journal of Mechanical Design

The dimension $d$ is therefore allowed to vary by $1.625 \mathrm{~mm}$ in the worst case. The total allowed variation is $4.175 \mathrm{~mm}$. The results have a direct influence on the setting of tolerances and the question whether those need to be symmetric.

For the multi-dimensional and multi-functional requirement problem the robustness radius can be calculated analogously; for example using the definition of the Euclidean distance.

$$
r_{R}=\min \left(\sqrt{\sum_{i}^{n}\left(x_{\text {nominal }_{i}}-\left(x_{i} \mid f(X)=f_{\text {limit }}\right)\right)^{2}}\right)
$$

The volume of the feasible space, which Suh calls design range [24], for $n$ independent variables and $\mathrm{n}$ functional requirements is a metric that describes the entire solution space that fulfills the constraints imposed onto the design by the functional requirements. This volume can be empty if there is no solution or infinite if one or more independent variables are unbounded. In the latter case it makes sense to constrain the independent variables to reasonable values. Furthermore, the volume is dependent on the number and selection of DPs. Figure 4 shows an example in the case of 2 design parameters and 2 functional requirements.

Corresponding author: Göhler, Simon Moritz MD-16-1166 (Research paper) 20 of 42 


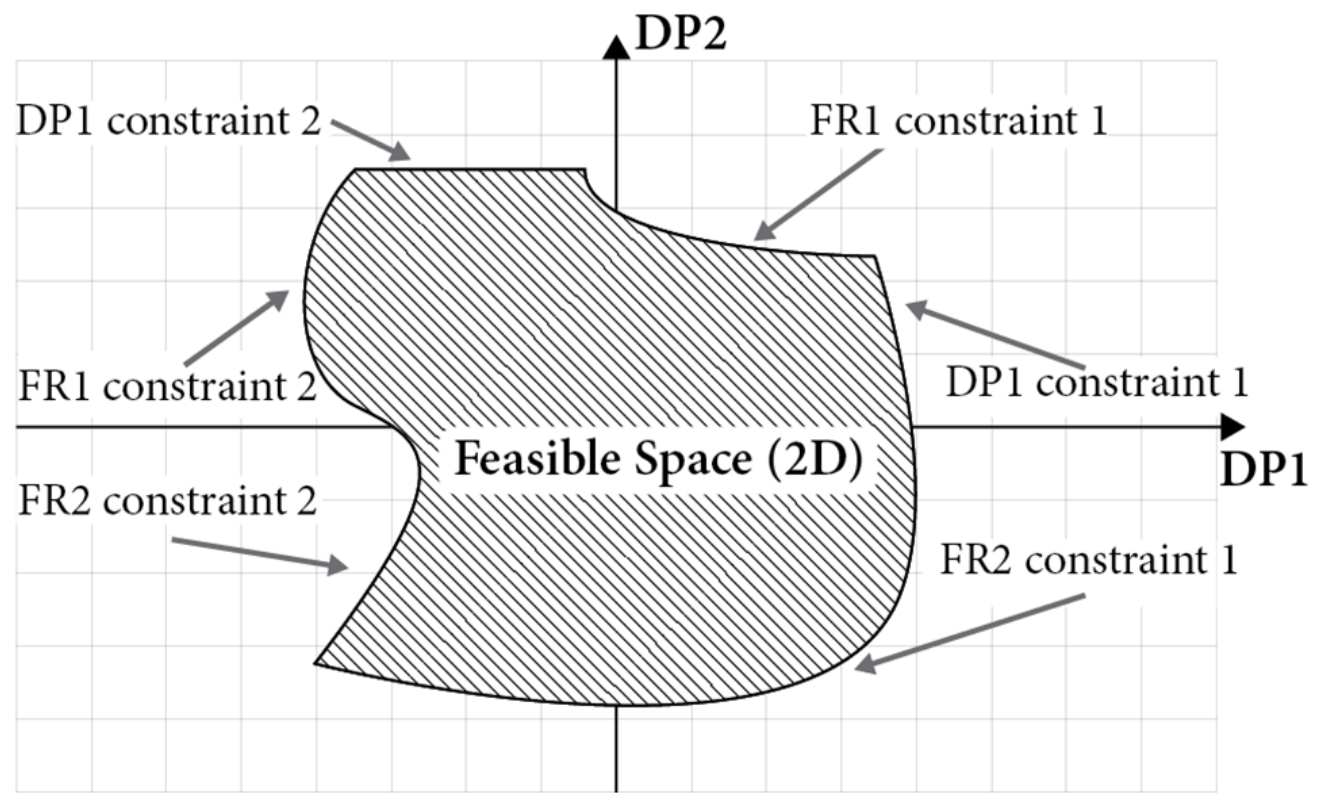

Figure 4: Example for a feasible design space in 2D

Frey et al. [30] discuss various methods to compute the volume of this polytope that forms the feasible design space. One of them is a method proposed by Lasserre [31] which evaluates a set of linear inequalities of the form $A x \leq b$.

$$
\operatorname{Vol}(n, A, b)=\frac{1}{n} \sum_{p=1}^{m} \frac{b_{p}}{\left|A_{p, q}\right|} \cdot \operatorname{Vol}(n-1, \tilde{A}, \tilde{b})
$$

The calculation is done recursively with $\tilde{A} x \leq \tilde{b}$ representing the system reduced by $x_{q}$ where the indices $m, n$ are the dimensions of the matrix $A$. Using Lasserre's theorem for the Toyota gas pedal case with the two functional requirements of the return moment and the bending stress yields a feasible space of

$$
\mathrm{Vol} \approx 7500 \mathrm{Nmm}^{6}
$$

This volume of the feasible space is independent of the nominal configuration of the design parameters which means that it cannot be used for parameter design 
optimization. However, the metric can be used to determine the influence of a constraint and to compare designs with a similar composition of influencing DPs. Further, the value can be normalized with the system range to make it comparable between designs or to calculate the likelihood of fulfilling the requirements under the assumption of uniform distribution of the DPs [30].

The metrics based upon allowed variation give the possibilities to analyze the robustness of a function towards a single and sets of independent variables, but also the robustness of a product or system consisting of multiple functions that need to be fulfilled simultaneously. The information about couplings is implicitly included in the formulation of the constraints imposed by the functional requirements.

\section{Summary:}

\begin{tabular}{|c|c|c|c|c|c|}
\hline \multicolumn{2}{|c|}{ Necessary information entities } & \multicolumn{2}{c|}{$\begin{array}{r}\text { Level of complexity (\# of functions / \# of } \\
\text { independent Variables) }\end{array}$} \\
\hline $\begin{array}{c}\text { Model/ } \\
\text { Experiment }\end{array}$ & $\begin{array}{c}\text { Functional } \\
\text { limits }\end{array}$ & $\begin{array}{c}\text { Expected / } \\
\text { measured } \\
\text { variation }\end{array}$ & $1 / 1$ & $1 / \mathrm{n}$ & $\mathrm{n} / \mathrm{n}$ \\
\hline$\checkmark$ & $\checkmark$ & - & $\checkmark$ & $\checkmark$ & $\checkmark$ \\
\hline
\end{tabular}

\subsection{Functional expectancy and dispersion robustness metrics}

The robustness metrics of this class are based on the evaluation of the two statistical moment measures expectancy and dispersion (variance) to describe the robustness of a function. For example, Robust Design pioneer Taguchi proposed the Signal-to-Noise ratio as robustness metric which builds upon the related ideas of quality loss and the mean square deviation [1], [2], [12] which again refer to the expectancy and variance of the functional performance. As opposed to metrics based on the size of the 
feasible design space as described in 4.2 these metrics do not require information about the functional requirements (limits).

To evaluate the expected functional performance, variance and associated robustness metrics in this category, a model or experiment and probabilistic information (in the form of probability density functions) of the stochastic variation of the independent variables (design parameter and noise factors) is necessary (information entities (1) and (3)). However, 'calculating these measures [functional expectancy and variance] analytically is almost always impossible' [8]. An alternative way is therefore to use approximations usually using Taylor expansion [32]. In the case that measurement data is available for the performance of a function or can be generated by an experiment or an adequate surrogate model the expectancy and dispersion measures can be calculated from the data samples. The ingoing variation can either be natural (known or unknown from the observed process) or estimated. The mean, variance and standard deviation can be calculated as follows (Equ. 14 - 16 respectively):

$$
\begin{gathered}
\mu(y)=\int f(X) \cdot p(\mathrm{X}) d \mathrm{X} \\
V(y)=\int(f(X)-E(y))^{2} \cdot p(\mathrm{X}) d \mathrm{X} \\
\sigma=\sqrt{\mathrm{V}}=\sqrt{\int(\mathrm{f}(\mathrm{X})-\mathrm{E}(\mathrm{y}))^{2} \cdot \mathrm{p}(\mathrm{X}) \mathrm{dX}}
\end{gathered}
$$

In classical robustness optimization algorithms, the mean's distance to the target and the variance of a function is optimized simultaneously, where weighting factors determine the prioritization between these two objectives. If the maximum and 
ASME Journal of Mechanical Design

minimum variation of the independent variables are known, for example, due to quality control and subsequent scrap, the probabilistic problem becomes a deterministic one and the maximum spread of the function performance can be calculated.

Functional expectancy and dispersion robustness metrics can be evaluated to describe the robustness of a function overall and to variation in single or sets of independent variables (DPs or noise factors). In those cases the conditional expectancy or variance is calculated.

To illustrate these different levels consider again the case of the Toyota gas pedal case. To determine the influence of the dimension $h$ on the bending stress of the friction shoe, or in other words to determine the robustness of the part integrity towards variation in the dimension $h$, the conditional variance can be calculated as the variation of the average of the bending stress for constant values of $h$ :

$$
V_{h}\left(E_{\sim h}\left(\sigma_{b} \mid h\right)\right)=0.3(M P a)^{2}
$$

From the ANOVA HDMR decomposition follows that the sum of all conditional variances - of the main effects plus all existing interactions effects - gives the total variance of the function [9].

$$
\begin{gathered}
\mathrm{V}(\mathrm{y})=\sum_{\mathrm{i}=1}^{\mathrm{n}} \mathrm{V}_{\mathrm{i}}+\sum_{\mathrm{i}=1}^{\mathrm{n}-1} \sum_{\mathrm{j}=\mathrm{i}+1}^{\mathrm{n}} \mathrm{V}_{\mathrm{ij}}+\cdots+\mathrm{V}_{12 \ldots \mathrm{n}} \\
V\left(\sigma_{b}\right)=31.1(\mathrm{MPa})^{2} \\
V\left(\mathrm{M}_{\text {return }}\right)=98434(\mathrm{Nmm})^{2}
\end{gathered}
$$

The value of robustness metrics that are based on the expectancy measure indicate if a functional performance is on target and can be used to calculate the bias. 
ASME Journal of Mechanical Design

The variance on the other hand - as calculated in equations $(19)+(20)$ for the bending stress and the return moment respectively - is difficult to put into perspective without knowledge about the functional requirements and their quality loss away from the target. However, valid comparisons of the robustness of two concepts or for different sets of variations in the independent variables are possible.

Summary:

\begin{tabular}{|c|c|c|c|c|c|}
\hline \multicolumn{3}{|c|}{ Necessary information entities } & \multicolumn{2}{c|}{$\begin{array}{r}\text { Level of complexity (\# of functions / \# of } \\
\text { independent Variables) }\end{array}$} \\
\hline $\begin{array}{c}\text { Model/ } \\
\text { Experiment }\end{array}$ & $\begin{array}{c}\text { Functional } \\
\text { limits }\end{array}$ & $\begin{array}{c}\text { Expected / } \\
\text { measured } \\
\text { variation }\end{array}$ & $1 / 1$ & $1 / \mathrm{n}$ & $\mathrm{n} / \mathrm{n}$ \\
\hline$\checkmark$ & - & $\checkmark$ & $\checkmark$ & $\checkmark$ & $\checkmark$ \\
\hline
\end{tabular}

\subsection{Probability of functional compliance robustness metrics}

Robustness metrics belonging to this class evaluate the probability that one or more functions fulfill their requirements under stochastic variation in the independent variables. For the assessment of the probabilities, detailed knowledge about the dependencies between independent variables and functions as well as information about the functional limits (LSL and USL) and the variation of the independent variables in the form of probability density functions is necessary (information entities (1), (2) and (3) respectively).

Under the assumption that the functional output is normally distributed, the probability of functional compliance (or yield rate in a production setting) can directly be calculated from the mean and variance. With knowledge about conditional variances it is possible to derive the probability of compliance of a function $j$ depending on the variation in single or sets of independent variables (Equ. $21+22$ ). Further, in the case 
ASME Journal of Mechanical Design

that the coupling between functions is known the conditional probabilities can be derived to calculate the joint probability, i.e. the likelihood of functions being satisfactory fulfilled simultaneously (Equ. 23). In that way the robustness of multifunctional systems can be evaluated.

$$
\begin{gathered}
\mathrm{P}_{i j}=\operatorname{Pr}\left[L S L_{j} \leq f_{j}\left(x_{i}\right) \leq U S L_{j}\right] \\
\mathrm{P}_{j}=\operatorname{Pr}\left[L S L_{j} \leq f_{j}(X) \leq U S L_{j}\right] \\
\mathrm{P}=\operatorname{Pr}\left[L S L_{j} \leq f_{j}(X) \leq U S L_{j}\left|L S L_{k \neq j} \leq f_{k \neq j}(X) \leq U S L_{k \neq j}\right| \ldots\right]
\end{gathered}
$$

Taking the Toyota gas pedal with described dimensions and stochastic variations, the following probabilities and conditional probabilities can be calculated as examples to describe their implications and differences.

$$
\begin{gathered}
\operatorname{Pr}\left[\sigma_{b} \leq \sigma_{\text {max }_{\text {nom }}}\right]=0.99 \\
\operatorname{Pr}\left[\sigma_{b} \leq \sigma_{\text {max }}\right]=0.94 \\
\operatorname{Pr}\left[0 \leq M_{\text {return }} \leq M_{\text {return }}\right. \text { max } \\
\operatorname{Pr}\left[0 \leq M_{\text {return }} \leq M_{\text {return }_{\text {max }}} \mid \sigma_{b} \leq \sigma_{\text {max }}\right]=0.71
\end{gathered}
$$

The probabilities in equation $24+25$ describe the likelihood of the bending stress being below $\sigma_{\max }$ as functional requirement neglecting and considering the variation in the yield stress respectively. The difference of $5 \%$ relates to the increase in probability of functional compliance if the yield stress was not subject to variation. Equation 26 describes the likelihood that the return moment is within the limits. Both, the probability of functional compliance for the bending stress and the return moment, were evaluated independently without taking the coupling between them into consideration. The last probability (Equ. 27) is the conditional probability that both 
ASME Journal of Mechanical Design

requirements are fulfilled simultaneously, which is lower than the independent probabilities. This demonstrates the error for the assumption of functional independence.

Summary:

\begin{tabular}{|c|c|c|c|c|c|}
\hline \multicolumn{3}{|c|}{ Necessary information entities } & \multicolumn{2}{c|}{$\begin{array}{r}\text { Level of complexity (\# of functions / \# of } \\
\text { independent Variables) }\end{array}$} \\
\hline $\begin{array}{c}\text { Model/ } \\
\text { Experiment }\end{array}$ & $\begin{array}{c}\text { Functional } \\
\text { limits }\end{array}$ & $\begin{array}{c}\text { Expected / } \\
\text { measured } \\
\text { variation }\end{array}$ & $1 / 1$ & $1 / \mathrm{n}$ & $\mathrm{n} / \mathrm{n}$ \\
\hline$\checkmark$ & $\checkmark$ & $\checkmark$ & $\checkmark$ & $\checkmark$ & $\checkmark$ \\
\hline
\end{tabular}

\section{DISCUSSION}

This section reflects on the verification and validation of the classification scheme offered. This is followed by a summary of the classes of robustness metrics in terms of their implications for defining robustness.

\subsection{Verification and Validation of Classification Scheme}

By assessing the different robustness metrics by their meaning in the TFM it was possible to place them into the four classes without ambiguity. The fact that the classes were mutually exclusive meaning that no metrics fit in more than one class is a sign of the strength of the classification scheme and can be considered as a form of verification [33]. The classification scheme was also deemed verified in terms of its 'completeness', in the sense that all metrics were able to be classified into one of the four classes. The fact that the classification scheme was derived from the TFM enables the metrics to be easily interpreted during the robust design process, thus ensuring the applicability of the scheme.

Corresponding author: Göhler, Simon Moritz MD-16-1166 (Research paper) 27 of 42 
ASME Journal of Mechanical Design

In extension to this theoretical verification, the validity of the classification scheme was furthermore evaluated based on the example of the Toyota gas pedal. Its robustness could be easily and clearly quantified using metrics from each of the four classes. It was found that the individual classes represent different interpretations and facets of robustness which have different fields of application within Robust Design.

\subsection{Facets of Robustness}

The analysis of the different robustness metrics mentioned in literature revealed the 4 classes: Sensitivity, Size of the feasible design space, Functional expectancy and dispersion and Probability of functional compliance robustness metrics.

Sensitivity robustness metrics address the general robustness of a concept independent of the specified functional requirements and expected variation. The metrics measure the general capability of a design to dampen or amplify variation. This view on robustness is favorable in earlier design stages when requirements as well as mission profiles and means of production are still unfixed and flexible. Especially in the concept selection phase, quantified knowledge about the inherent robustness of the different design solutions is of high value.

Metrics from the class of size of feasible design space include information about the final requirements which the functions are evaluated against. They quantify the design feasibility taking all functional requirements into consideration and measure therefore the robustness of a design itself, independent of the variation it is exposed to. 
ASME Journal of Mechanical Design

Robustness metrics using functional expectancy and dispersion measures on the other hand address the spread of the performance of functions resulting from variation in the influencing factors and therefore the robustness of a function.

Finally, robustness metrics using the probability of fulfilling the functional requirements under the influence of variation measure the robustness of the product itself and reflect the sum of the sensitivity, requirements and ingoing variation.

\section{CONCLUDING REMARKS AND OUTLOOK}

In this contribution we systematically reviewed the literature to extract all the different metrics to describe robustness in connection with product development and engineering design. 38 unique metrics were identified and their mathematical descriptions analyzed with respect to their required information and level of addressed complexity. The analysis revealed 4 distinct meanings of robustness metrics which describe 4 different facets of quantifying robustness:

1. Sensitivity robustness metrics $\rightarrow$ robustness of a concept

2. Size of the feasible design space robustness metrics $\rightarrow$ robustness of a design

3. Functional expectancy and dispersion robustness metrics $\rightarrow$ robustness of a function

4. Probability of functional compliance robustness metrics $\rightarrow$ robustness of a product 
ASME Journal of Mechanical Design

The authors believe that this categorization removes the ambiguity of the term 'robustness' ensuring an unambiguous communication allowing the formal introduction of robustness requirements to specification documents and design targets.

Another important contribution of this research is the list of metrics and how they are calculated which gives a comprehensive overview for scholars and practitioners of how robustness can be quantified. The choice of adequate metrics is especially important for simulation-based and computer-aided design and design optimization to ensure viable solutions. Also, the derivation of new metrics can be guided and driven by the classification of metrics and the differentiation of facets of quantifying robustness presented in this paper.

Further research is necessary to close the gap between these objective, quantifiable metrics to proxies (or leading indicators) that are based on good design practice [34], [35] such as the Variation risk Priority Number [36], [37], the number of over-constraints [3], [38] as well as the Contradiction Index [39]. These proxies play a particularly important role in early design phases where there are no mathematical descriptions of the functions available. The development of further proxies based on objective robustness metrics, as described in this article would be of high value for engineering designers for the quick estimation of robustness without the need of high fidelity models.

\section{ACKNOWLEDGMENT}

The authors would like to thank Novo Nordisk for their insights and financial support of the DTU-NN Robust Design program.

Corresponding author: Göhler, Simon Moritz MD-16-1166 (Research paper) 30 of 42 
ASME Journal of Mechanical Design

\section{NOMENCLATURE}

\begin{tabular}{|c|c|}
\hline$A_{0}$ & Maximum loss at variation $\Delta_{0}$ \\
\hline ANOVA & Analysis of variance \\
\hline$D$ & Diagonal matrix \\
\hline$\Delta_{i}$ & Perturbation \\
\hline$D P$ & Design parameter \\
\hline$E$ & Expected value \\
\hline$f$ & Function \\
\hline$F R$ & Functional requirement \\
\hline HDMR & High-dimensional model representation \\
\hline$J$ & Jacobian matrix \\
\hline$\lambda$ & Eigenvalue \\
\hline LRL & Lower requirement Limit \\
\hline LSL & Lower specification limit \\
\hline LTB & Larger-the-better requirement \\
\hline$m$ & Functional target \\
\hline$\mu$ & Mean \\
\hline$N F$ & Noise factor \\
\hline
\end{tabular}


ASME Journal of Mechanical Design

NTB Nominal-the-best requirement

$p($.$) \quad Probability density function$

$\operatorname{Pr} \quad$ Probability

$\Sigma \quad$ Covariance matrix

$\sigma \quad$ Standard deviation

$\sigma_{a} \quad$ Adjusted standard deviation

STB Smaller-the-better requirement

TFM Transfer function model

URL Upper requirement Limit

USL $\quad$ Upper specification limit

V Variation

Vol Volume of $\mathrm{n}$ dimensional polyhedron

w Weighting factor

$x_{i} \quad \mathrm{i}^{\text {th }}$ independent variable

$X \quad$ Vector of $\mathrm{i}$ independent variables

y Functional output, dependent variable

Corresponding author: Göhler, Simon Moritz MD-16-1166 (Research paper) 32 of 42 


\section{APPENDIX}

Table 5: List of robustness metrics

\begin{tabular}{|c|c|c|c|c|c|c|c|c|c|}
\hline \multirow[b]{2}{*}{$\#$} & \multirow[b]{2}{*}{ Name } & \multirow[b]{2}{*}{ Mathematical Expression } & \multicolumn{3}{|c|}{ Necessary information entities } & \multicolumn{2}{|c|}{ Level of complexity } & \multirow[b]{2}{*}{$\begin{array}{l}\text { Robustness } \\
\text { metric } \\
\text { class }\end{array}$} & \multirow[b]{2}{*}{ Reference } \\
\hline & & & $\begin{array}{c}\text { Model / } \\
\text { Experiment }\end{array}$ & $\begin{array}{l}\text { Functional } \\
\text { Limits }\end{array}$ & $\begin{array}{l}\text { Expected / } \\
\text { measured } \\
\text { variation }\end{array}$ & $\begin{array}{l}\text { Independent } \\
\text { variables } \\
\text { (single / } \\
\text { multiple) }\end{array}$ & $\begin{array}{l}\text { Dependent } \\
\text { variables } \\
\text { (single / } \\
\text { multiple) }\end{array}$ & & \\
\hline 1 & $\begin{array}{l}\text { Nominal range sensitivity } \\
\text { (NRS) relative to } \\
\text { perturbation }\end{array}$ & $N R S_{i}=\frac{\frac{f\left(x_{1}, \ldots, x_{i} \cdot\left(1+\Delta_{i}\right), \ldots, x_{n}\right)}{f(X)}-1}{\Delta_{i}}$ & $\checkmark$ & - & - & single & single & Sensitivity & [10] \\
\hline 2 & $\begin{array}{l}\text { Nominal range sensitivity } \\
\text { (NRS) absolute }\end{array}$ & $N R S_{i}=\left(\frac{f\left(x_{1}, \ldots, x_{i} \cdot\left(1+\Delta_{i}\right), \ldots, x_{n}\right)}{f(X)}-1\right) \cdot 100 \%$ & $\checkmark$ & - & - & single & single & Sensitivity & [10] \\
\hline 3 & $\begin{array}{l}\text { Elementary effects / } \\
\text { Nominal influence }\end{array}$ & $E E_{i}^{a b s}=\frac{1}{r} \sum_{j=1}^{r}\left|E E_{i}^{j}\right|$ with $\left|E E_{i}^{j}\right|=\frac{f\left(x_{1}, \ldots, x_{i} \cdot\left(1+\Delta_{j}\right), \ldots, x_{n}\right)-f(X)}{x_{i} \cdot \Delta_{j}}$ & $\checkmark$ & - & - & single & single & Sensitivity & [9], [40] \\
\hline 4 & Partial derivative & $S_{i}=\frac{\partial f}{\partial x_{i}}(X)$ & $\checkmark$ & - & - & single & single & Sensitivity & $\begin{array}{l}\text { [9], [13], } \\
{[20],[41]}\end{array}$ \\
\hline \multirow[b]{2}{*}{5} & \multirow{2}{*}{$\begin{array}{l}\text { Normalized partial } \\
\text { derivative / Sensitivity } \\
\text { coefficient }\end{array}$} & $S_{\text {imean }}=\frac{\partial f}{\partial x_{i}}(X) \cdot \frac{x_{i}}{f(X)}$ & $\checkmark$ & - & - & single & single & Sensitivity & $\begin{array}{c}{[10],} \\
{[40],[20]}\end{array}$ \\
\hline & & $S_{i s t d}=\frac{\partial f}{\partial x_{i}}(X) \cdot \frac{\sigma\left(x_{i}\right)}{\sigma(f)}$ & $\checkmark$ & - & $(\checkmark)$ & single & single & Sensitivity & $\begin{array}{c}{[10],[13],} \\
{[40]}\end{array}$ \\
\hline 6 & Importance Factor & $I_{i}=\frac{\left(\frac{\partial f}{\partial x_{i}}(X)\right)^{2}}{\sum_{j=1}^{N}\left(\frac{\partial f}{\partial x_{j}}(X)\right)^{2}}$ & $\checkmark$ & - & - & single & single & Sensitivity & [42] \\
\hline 7 & FAST Index & $S_{\omega l}^{(i)}=\frac{\sum_{p}\left(\left|A_{p \omega l}^{(i)}\right|^{2}+\left|B_{p \omega l}^{(i)}\right|^{2}\right)}{\sum_{j}\left(\left|A_{j}^{(i)}\right|^{2}+\left|B_{j}^{(i)}\right|^{2}\right)}$ & $\checkmark$ & - & - & multiple & single & Sensitivity & $\begin{array}{c}{[9],[43],} \\
{[44]}\end{array}$ \\
\hline 8 & Regression coefficients & $\beta_{i}=\frac{\sum_{j}\left[\left(\left(x_{i_{j}}-\mu_{x_{i}}\right) \cdot\left(y-\mu_{y}\right)\right)\right]^{2}}{\sum_{j}\left(x_{i_{j}}-\mu_{x_{i}}\right)^{2}}$ & $\checkmark$ & - & $(\checkmark)$ & $\begin{array}{c}\text { single/ } \\
\text { (multiple) }\end{array}$ & single & Sensitivity & $\begin{array}{c}{[13],[19],} \\
{[32]}\end{array}$ \\
\hline 9 & $\begin{array}{l}\text { Standardized regression } \\
\text { coefficients }\end{array}$ & $\operatorname{SRC}\left(y, x_{i}\right)=\beta_{i} \frac{\sigma_{x_{i}}}{\sigma_{y}}$ & $\checkmark$ & - & $(\checkmark)$ & single & single & Sensitivity & [45] \\
\hline 10 & $\begin{array}{l}\text { Spearman Robustness } \\
\text { Index }\end{array}$ & $S R I=\min \left|\frac{1}{\rho_{x_{i}} \cdot \beta_{x_{i}} \cdot \mu_{x_{i}}}\right|$ & $\checkmark$ & - & $(\checkmark)$ & single & single & Sensitivity & [19], [46] \\
\hline 11 & $\begin{array}{l}\text { Spearman Robustness } \\
\text { Index } 2\end{array}$ & $S R I=\frac{1}{\sigma_{\rho} \sigma_{\beta_{x_{i}} \cdot \mu_{x_{i}}}}$ & $\checkmark$ & - & $(\checkmark)$ & single & single & Sensitivity & [46] \\
\hline
\end{tabular}




\begin{tabular}{|c|c|c|c|c|c|c|c|c|c|}
\hline 12 & Robustness Index & $\eta=\frac{1}{N} \sum_{i=1}^{N} \frac{\left\|f\left(x_{1}, \ldots, x_{i} \cdot(1+\Delta), \ldots, x_{n}\right)-f(X)\right\|}{\|f(X)\|}$ & $\checkmark$ & - & - & single & single & Sensitivity & [47] \\
\hline 13 & $\begin{array}{l}\text { Euclidean norm of } \\
\text { Jacobian }\end{array}$ & $\|J\|_{2}=\sqrt{\lambda_{\max }\left(A^{T} A\right)}$ & $\checkmark$ & - & - & multiple & single & Sensitivity & [48], [49] \\
\hline 14 & $\begin{array}{l}\text { Frobenius norm of } \\
\text { Jacobian }\end{array}$ & $\|J\|_{F}=\left(\sum_{i, j}\left|a_{i j}\right|^{2}\right)^{\frac{1}{2}}$ & $\checkmark$ & - & - & multiple & single & Sensitivity & [48] \\
\hline 15 & Condition Number & $\kappa=\|J\|_{2}\left\|J^{-1}\right\|_{2}$ & $\checkmark$ & - & - & multiple & single & Sensitivity & [48]-[50] \\
\hline 16 & $\begin{array}{l}\text { Objective Robustness } \\
\text { Index }\end{array}$ & $\max _{\Delta p} R(\Delta p)=\left[\sum_{i=1}^{n}\left|\frac{f_{i}\left(X_{0}+\Delta\right)-f_{i}(X)}{\Delta f_{i, l i m i t}}\right|\right]^{\frac{1}{2}}$ & $\checkmark$ & - & - & single & single & Sensitivity & [51] \\
\hline 17 & $\begin{array}{l}\text { Euclidean distance } \\
\text { (Robustness radius) }\end{array}$ & $r_{E}=\min _{X_{j}:\left(f_{i j}\left(X_{j}\right)=f_{\max }\right) \vee\left(f_{i j}\left(X_{j}\right)=f_{\min }\right)} \sqrt{\left(X_{j}-X_{\text {nom }}\right) D^{-1}\left(X_{j}-X_{\text {nom }}\right)^{T}}$ & $\checkmark$ & $\checkmark$ & - & multiple & multiple & $\begin{array}{l}\text { Feasible } \\
\text { design } \\
\text { space }\end{array}$ & $\begin{array}{c}\text { [52], [53], } \\
{[54]}\end{array}$ \\
\hline 18 & Mahalanobis distance & $r_{M}=\min _{X_{j}:\left(f_{i j}\left(X_{j}\right)=f_{\max }\right) \vee\left(f_{i j}\left(X_{j}\right)=f_{\min }\right)} \sqrt{\left(X_{j}-X_{\text {nom }}\right) \Sigma^{-1}\left(X_{j}-X_{\text {nom }}\right)^{T}}$ & $\checkmark$ & $\checkmark$ & - & multiple & multiple & $\begin{array}{l}\text { Feasible } \\
\text { design } \\
\text { space }\end{array}$ & $\begin{array}{c}\text { [29], [52], } \\
{[55]}\end{array}$ \\
\hline 19 & Feasible volume & $\operatorname{Vol}(n, A, b)=\frac{1}{n} \sum_{p=1}^{m} \frac{b_{p}}{\left|A_{p, q}\right|} \cdot \operatorname{Vol}(n-1, \tilde{A}, \tilde{b})$ & $\checkmark$ & $\checkmark$ & - & multiple & multiple & $\begin{array}{l}\text { Feasible } \\
\text { design } \\
\text { space }\end{array}$ & $\begin{array}{c}\text { [30], [53], } \\
{[56]}\end{array}$ \\
\hline 20 & Min-Max Interval & $M M I=f_{\max }-f_{\min }$ & $\checkmark$ & - & $\checkmark$ & multiple & single & $\begin{array}{l}\text { Functional } \\
\text { expectancy } \\
\text { and } \\
\text { dispersion }\end{array}$ & {$[8],[57]$} \\
\hline 21 & Sensitivity Index (2) & $S I=\frac{f_{\max }-f_{\min }}{f_{\max }}$ & $\checkmark$ & - & $\checkmark$ & multiple & single & $\begin{array}{l}\text { Functional } \\
\text { expectancy } \\
\text { and } \\
\text { dispersion }\end{array}$ & {$[32]$} \\
\hline 22 & Percentile difference & $\Delta y_{5 \%}^{95 \%}=y^{95 \%}-y^{5 \%}$ & $\checkmark$ & - & $\checkmark$ & multiple & single & $\begin{array}{l}\text { Functional } \\
\text { expectancy } \\
\text { and } \\
\text { dispersion }\end{array}$ & [58] \\
\hline 23 & Variance & $\begin{array}{c}V(y)=\int(f(X)-E(y))^{2} \cdot p(X) d X \\
V(y)=\sum_{i=1}^{n}\left(\frac{\partial f}{\partial x_{i}}\right)^{2} V\left(X_{i}\right), \text { for independent } X_{i} \\
\left.V(y)=\sum_{i=1}^{n} V_{i}+\sum_{i=1}^{n-1} \sum_{j=i+1}^{n} V_{i j}+\cdots+V_{12 \ldots n} \text { (variance decomposition }(H D M R)\right)\end{array}$ & $\checkmark$ & - & $\checkmark$ & multiple & single & $\begin{array}{l}\text { Functional } \\
\text { expectancy } \\
\text { and } \\
\text { dispersion }\end{array}$ & $\begin{array}{c}{[8],[9],} \\
{[19],[13],} \\
{[59]}\end{array}$ \\
\hline
\end{tabular}




\begin{tabular}{|c|c|c|c|c|c|c|c|c|c|}
\hline 24 & Standard deviation & $\sigma=\sqrt{V}=\sqrt{\int(f(X)-E(y))^{2} \cdot p(X) d X}$ & $\checkmark$ & - & $\checkmark$ & multiple & single & $\begin{array}{l}\text { Functional } \\
\text { expectancy } \\
\text { and } \\
\text { dispersion }\end{array}$ & [9] \\
\hline 25 & Conditional variance & $V_{i 1 \ldots i s}=V_{X_{i 1 \ldots i s}}\left(E_{X_{\sim i 1 \ldots i s}}\left(y \mid X_{i 1 \ldots i s}\right)\right)$ & $\checkmark$ & - & $\checkmark$ & multiple & single & $\begin{array}{l}\text { Functional } \\
\text { expectancy } \\
\text { and } \\
\text { dispersion }\end{array}$ & $\begin{array}{c}{[9],[43],} \\
{[44]}\end{array}$ \\
\hline 26 & $\begin{array}{l}\text { Sensitivity Index / Sobol } \\
\text { Index }\end{array}$ & $S_{i 1 \ldots i s}=\frac{V_{i 1 \ldots i s}}{V}$ & $\checkmark$ & - & $\checkmark$ & multiple & single & $\begin{array}{l}\text { Functional } \\
\text { expectancy } \\
\text { and } \\
\text { dispersion }\end{array}$ & [9], [43] \\
\hline 27 & Uncertainty Importance & $I_{i}=\sqrt{V(y)-E\left[V\left(y \mid x_{i}\right)\right]}$ & $\checkmark$ & - & $\checkmark$ & multiple & single & $\begin{array}{l}\text { Functional } \\
\text { expectancy } \\
\text { and } \\
\text { dispersion }\end{array}$ & [9] \\
\hline 28 & Design Preference Index & $D P I=E[P(y)]=\int_{y-\Delta y}^{y} P(y) f(y) d y$ & $\checkmark$ & - & $\checkmark$ & multiple & single & $\begin{array}{l}\text { Functional } \\
\text { expectancy } \\
\text { and } \\
\text { dispersion } \\
\end{array}$ & [60] \\
\hline 29 & Function robustness & $f^{R}=\frac{1}{N} \sum_{i=1}^{N} \frac{\sigma_{f}}{\sigma_{x_{i}}}$ & $\checkmark$ & - & $\checkmark$ & multiple & single & $\begin{array}{l}\text { Functional } \\
\text { expectancy } \\
\text { and } \\
\text { dispersion }\end{array}$ & [61] \\
\hline 30 & Importance Index & $I I_{i}=\frac{\sigma_{x_{i}}^{2}}{\sigma_{y}^{2}}$ & $\checkmark$ & - & $\checkmark$ & multiple & single & $\begin{array}{l}\text { Functional } \\
\text { expectancy } \\
\text { and } \\
\text { dispersion }\end{array}$ & [32], [62] \\
\hline 31 & Expectancy measure & $F(x)=\int f(X) \cdot p(\mathrm{X}) d X$ & $\checkmark$ & - & $\checkmark$ & multiple & single & $\begin{array}{l}\text { Functional } \\
\text { expectancy } \\
\text { and } \\
\text { dispersion }\end{array}$ & {$[8],[63]$} \\
\hline 32 & Quality loss function & $\begin{array}{c}L(y)_{N T B}=\frac{A_{0}}{\Delta_{0}^{2}}(y-m)^{2} \\
L(y)_{S T B}=\frac{A_{0}}{\Delta_{0}^{2}}(y)^{2} \\
L(y)_{L T B}=A_{0} \Delta_{0}^{2}\left(\frac{1}{y}\right)^{2}\end{array}$ & $\checkmark$ & - & $\checkmark$ & multiple & single & $\begin{array}{l}\text { Functional } \\
\text { expectancy } \\
\text { and } \\
\text { dispersion }\end{array}$ & $\begin{array}{l}{[1],[2],} \\
{[12]}\end{array}$ \\
\hline 33 & Mean square deviation & $\begin{array}{c}M S D_{N T B}=\sigma_{a}^{2}+(\mu-m)^{2} \\
M S D_{S T B}=\sigma_{a}^{2}+\mu^{2} \\
M S D_{L T B}=\frac{1}{n} \sum_{i=1}^{n}\left(\frac{1}{y_{i}}\right)^{2}\end{array}$ & $\checkmark$ & - & $\checkmark$ & multiple & single & $\begin{array}{l}\text { Functional } \\
\text { expectancy } \\
\text { and } \\
\text { dispersion }\end{array}$ & $\begin{array}{c}{[1],[2],} \\
{[12]}\end{array}$ \\
\hline
\end{tabular}


ASME Journal of Mechanical Design

\begin{tabular}{|c|c|c|c|c|c|c|c|c|c|}
\hline 34 & Signal-to-Noise Ratio & $\begin{array}{c}S N R_{N T B}=10 \log _{10} \frac{\mu^{2}}{\sigma^{2}} \\
S N R_{S T B}=-10 \log _{10}\left(\sigma^{2}+\mu^{2}\right) \\
S N R_{L T B}=-10 \log _{10}\left[\frac{1}{n} \sum_{i=1}^{n}\left(\frac{1}{y_{i}}\right)^{2}\right]\end{array}$ & $\checkmark$ & - & $\checkmark$ & multiple & single & $\begin{array}{l}\text { Functional } \\
\text { expectancy } \\
\text { and } \\
\text { dispersion }\end{array}$ & $\begin{array}{c}{[1],[2],} \\
{[12]}\end{array}$ \\
\hline 35 & Weighted sum robustness & $R_{w}=w_{1} \cdot\left|\mu_{y}-m\right|+w_{2} \cdot \sigma_{y}$ & $\checkmark$ & - & $\checkmark$ & multiple & single & $\begin{array}{l}\text { Functional } \\
\text { expectancy } \\
\text { and } \\
\text { dispersion }\end{array}$ & [64] \\
\hline 36 & $\begin{array}{l}\text { Probabilistic robustness } \\
\text { threshold }\end{array}$ & $\operatorname{Pr}\left[L S L_{i}<f_{i}<U S L_{i}\right]$ & $\checkmark$ & $\checkmark$ & $\checkmark$ & multiple & multiple & $\begin{array}{l}\text { Probability } \\
\text { of } \\
\text { functional } \\
\text { compliance }\end{array}$ & {$[8],[58]$} \\
\hline 37 & $\begin{array}{l}\text { Design capability Indices / } \\
\text { Error margin index }\end{array}$ & $C_{d l}=\frac{\mu-L R L}{3 \sigma} ; C_{d u}=\frac{U R L-\mu}{3 \sigma} ; C_{d k}=E M I=\min \left\{C_{d l}, C_{d u}\right\}$ & $\checkmark$ & $\checkmark$ & $\checkmark$ & multiple & single & $\begin{array}{l}\text { Probability } \\
\text { of } \\
\text { functional } \\
\text { compliance }\end{array}$ & {$[65],[66]$} \\
\hline 38 & Information content & $I=\log \left(\frac{1}{p}\right)$ & $\checkmark$ & $\checkmark$ & $\checkmark$ & multiple & multiple & $\begin{array}{l}\text { Probability } \\
\text { of } \\
\text { functional } \\
\text { compliance }\end{array}$ & [24] \\
\hline
\end{tabular}




\section{REFERENCES}

[1] G. Taguchi, S. Chowdhury, and Y. Wu, Taguchi's quality engineering handbook. Hoboken, NJ: John Wiley \& Sons, 2005.

[2] M. S. Phadke, Quality Engineering using Robust Design. Prentice Hall, 1989.

[3] M. Ebro, T. J. Howard, and J. J. Rasmussen, "The foundation for robust design: Enabling robustness through kinematic design and design clarity," in Proceedings of International Design Conference, DESIGN, 2012, vol. DS 70, pp. 817-826.

[4] I. Gremyr, M. Arvidsson, and P. Johansson, "Robust Design Methodology: Status in the Swedish Manufacturing Industry," Qual. Reliab. Eng. Int., vol. 19, no. 4, pp. 285-293, Jul. 2003.

[5] A. C. Thornton, S. Donnelly, and B. Ertan, "More than Just Robust Design: Why Product Development Organizations Still Contend with Variation and its Impact on Quality," Research in Engineering Design, vol. 12. pp. 127-143, 2000.

[6] L. Krogstie, M. Ebro, and T. J. Howard, "How to implement and apply robust design: insights from industrial practice," Total Qual. Manag. Bus. Excell., no. August, pp. 1-19, Jul. 2014.

[7] S. M. Göhler, M. Ebro, and T. J. Howard, "Mechanisms and coherences of robust design methodology: a robust design process proposal," Total Qual. Manag. Bus. Excell., vol. 3363, no. May, pp. 1-21, 2016.

[8] H.-G. Beyer and B. Sendhoff, "Robust optimization - A comprehensive survey," Comput. Methods Appl. Mech. Eng., vol. 196, no. March 2007, pp. 3190-3218, Jul. 2007.

[9] A. Saltelli, M. Ratto, T. Andres, F. Campolongo, J. Cariboni, D. Gatelli, M. Saisana, and S. Tarantola, Global Sensitivity Analysis: The Primer. John Wiley \& Sons, 2008.

[10] H. C. Frey, S. R. Patil, C. H. Frey, and S. R. Patil, "Identification and Review of Sensitivity Analysis Methods," Risk Anal., vol. 22, no. 3, pp. 553-578, Jun. 2002.

[11] A. C. Thornton, Variation risk management: focusing quality improvements in product development and production. Hoboken, NJ: John Wiley \& Sons, 2004.

[12] W. Y. Fowlkes and C. M. Creveling, Engineering Methods for Robust Product Design. Addison-Wesley, 1995.

[13] T. Eifler, J. Mathias, R. Engelhardt, H. Kloberdanz, A. Bohn, and H. Birkhofer, "Evaluation of solution variants in Conceptual Design by means of adequate sensitivity indices," in ICED 11 - 18th International Conference on Engineering Design - Impacting Society Through Engineering Design, 2011, vol. 9, no. August, pp. $314-323$.

[14] C. Zang, M. I. Friswell, and J. E. Mottershead, "A review of robust optimal design and its application in dynamics," Computers \& Structures, vol. 83, no. 4-5. pp. 315-326, Jan-2005.

[15] T. E. Murphy, K.-L. Tsui, and J. K. Allen, "A review of robust design methods for multiple responses," Res. Eng. Des., vol. 15, no. 4, pp. 201-215, Sep. 2004.

[16] T. J. Robinson, C. M. Borror, and R. H. Myers, "Robust Parameter Design: A Review," Qual. Reliab. Eng. Int., vol. 20, no. 1, pp. 81-101, Feb. 2004.

[17] J. Biolchini, P. G. Mian, A. Candida, and C. Natali, "Systematic Review in Software

Corresponding author: Göhler, Simon Moritz MD-16-1166 (Research paper) 37 of 42 
Engineering," 2005.

[18] D. Hamby, "A comparison of sensitivity analysis techniques," Health Phys., pp. 120, 1995.

[19] J. C. Helton, J. D. Johnson, C. J. Sallaberry, and C. B. Storlie, "Survey of samplingbased methods for uncertainty and sensitivity analysis," Reliab. Eng. Syst. Saf., vol. 91, pp. 1175-1209, 2006.

[20] R. S. Hutcheson and D. A. Mcadams, "Sensitivity measures for use during conceptual design," Int. J. Des. Eng., vol. 5, no. 1, 2012.

[21] W. Chen, J. K. Allen, K.-L. Tsui, and F. Mistree, "A Procedure for Robust Design: Minimizing Variations Caused by Noise Factors and Control Factors," Journal of Mechanical Design, vol. 118, no. 4. p. 478, 1996.

[22] J. K. Allen, C. Seepersad, H. Choi, and F. Mistree, "Robust Design for Multiscale and Multidisciplinary Applications," J. Mech. Des., vol. 128, no. July 2006, p. 832, 2006.

[23] J. Y. Dantan, N. Gayton, A. J. Qureshi, M. Lemaire, and A. Etienne, "Tolerance analysis approach based on the classification of uncertainty (aleatory/epistemic)," Procedia CIRP, vol. 10, pp. 287-293, 2013.

[24] N. P. Suh, Axiomatic Design: Advances and Applications. New York: Oxford University Press, 2001.

[25] T. J. Howard, M. Ebro, T. Eifler, S. Petersen, S. M. Göhler, A. Christiansen, and A. Rafn, "The Variation Management Framework (VMF) for Robust Design," in 1st International Symposium on Robust Design, 2014, no. August, pp. 1-9.

[26] Z. Dai, M. J. Scott, and Z. P. Mourelatos, "Incorporating epistemic uncertainty in robust design," in Proceedings of the ASME 2003 International Design Engineering Technical Conferences \& Computers and Information in Engineering Conference, 2003, pp. 85-95.

[27] Z. Hu, X. Du, N. S. Kolekar, and A. Banerjee, "Robust design with imprecise random variables and its application in hydrokinetic turbine optimization," Eng. Optim., vol. 46, no. 3, pp. 393-419, 2013.

[28] The Guardian, "Toyota's sticky accelerator problem," 2010. [Online]. Available: http://www.theguardian.com/business/interactive/2010/feb/04/toyotaautomotive-industry. [Accessed: 23-Feb-2016].

[29] P. C. Mahalanobis, "On the generalised distance in statistics," Proc. Natl. Inst. Sci. India, vol. 12, pp. pp. 49-55, 1936.

[30] D. D. Frey, E. Jahangir, and F. Engelhardt, "Computing the information content of decoupled designs," Res. Eng. Des. - Theory, Appl. Concurr. Eng., vol. 12, no. 2, pp. 90-102, 2000.

[31] J. B. Lasserre, "An analytical expression and an algorithm for the volume of a convex polyhedron in Rn," J. Optim. Theory Appl., vol. 39, no. 3, pp. 363-377, 1983.

[32] D. M. Hamby, "A review of techniques for parameter sensitivity analysis of environmental models," Environmental Monitoring and Assessment, vol. 32, no.

2. Kluwer Academic Publishers, pp. 135-154, Sep-1994.

[33] B. Minto, The Pyramid Principle: Logic in Writing and Thinking. Pearson Education, 
2009.

[34] G. Pahl, W. Beitz, J. Feldhusen, and K.-H. Grote, Engineering design: a systematic approach. Springer Science \& Business Media, 2007.

[35] B. Matthiassen, "Design for Robustness and Reliability: Improving the Quality Consciousness in Engineering Design.," Technical University of Denmark, 1997.

[36] A. Chakhunashvili, P. Johansson, and B. Bergman, "Variation mode and effect analysis," in Reliability and Maintainability, 2004 Annual Symposium-RAMS. IEEE, 2004, pp. 364-369.

[37] P. Johannesson, B. Bergman, T. Svensson, M. Arvidsson, Å. Lönnqvist, S. Barone, and J. De Maré, "A robustness approach to reliability," Qual. Reliab. Eng. Int., vol. 29, no. January 2012, pp. 17-32, 2013.

[38] M. Ebro and T. J. Howard, "Robust design principles for reducing variation in functional performance," J. Eng. Des., pp. 1-18, 2016.

[39] S. M. Göhler and T. J. Howard, "The Contradiction Index - a new Metric combining System Complexity and Robustness for early Design Stages," in Proceedings of the ASME 2015 International Design Engineering Technical Conferences \& Computers and Information in Engineering Conference, 2015, pp. 1-10.

[40] A. Charzyńska, A. Nalęcz, M. Rybiński, A. Gambin, and M. Medical, "Sensitivity analysis of mathematical models of signaling pathways," Biotechnologia, vol. 93, no. 3, pp. 291-308, 2012.

[41] J. S. Han and B. M. Kwak, "Robust optimization using a gradient index: MEMS applications," Struct. Multidiscip. Optim., vol. 27, no. 6, pp. 469-478, 2004.

[42] S. Bhattacharjya and S. Chakraborty, "Improved robust design optimisation of structures," Proc. ICE - Eng. Comput. Mech., vol. 164, no. 1, pp. 47-57, Mar. 2011.

[43] I. M. Sobol, "Global sensitivity indices for nonlinear mathematical models and their Monte Carlo estimates," Math. Comput. Simul., vol. 55, no. 1-3, pp. 271280, 2001.

[44] R. I. Cukier, H. B. Levine, and K. E. Shuler, "Nonlinear sensitivity analysis of multiparameter model systems," J. Comput. Phys., vol. 26, no. 1, pp. 1-42, 1978.

[45] G. Manache and C. S. Melching, "Identification of reliable regression- and correlation-based sensitivity measures for importance ranking of water-quality model parameters," Environ. Model. Softw., vol. 23, no. 5, pp. 549-562, May 2008.

[46] M. C. W. Lee, D. W. Kelly, R. Degenhardt, and R. S. Thomson, "A study on the robustness of two stiffened composite fuselage panels," Compos. Struct., vol. 92, no. 2, pp. 223-232, Jan. 2010.

[47] S. Kwag and S.-Y. Ok, "Robust design of seismic isolation system using constrained multi-objective optimization technique," KSCE J. Civ. Eng., vol. 17, no. 5, pp. 1051-1063, Jun. 2013.

[48] S. Caro, F. Bennis, and P. Wenger, "Tolerance Synthesis of Mechanisms: A Robust Design Approach," J. Mech. Des., vol. 127, no. January 2005, p. 86, 2005.

[49] S. Caro, F. Bennis, and P. Wenger, "Comparison of Robustness Indices and Introduction of a Tolerance Synthesis Method for Mechanisms," Can. Congr. Appl. Mech., pp. 3-4, 2005. 
[50] K.-L. L. Ting and Y. Long, "Performance Quality and Tolerance Sensitivity of Mechanisms," J. Mech. Des., vol. 118, no. March 1996, p. 144, 1996.

[51] M. Li, S. Azarm, and A. Boyars, "A New Deterministic Approach Using Sensitivity Region Measures for Multi-Objective Robust and Feasibility Robust Design Optimization," J. Mech. Des., vol. 128, no. 4, p. 874, 2006.

[52] B. Eslamnour and S. Ali, "Measuring robustness of computing systems," Simul. Model. Pract. Theory, vol. 17, no. 9, pp. 1457-1467, Oct. 2009.

[53] S. Gunawan and S. Azarm, "Non-Gradient Based Parameter Sensitivity Estimation for Single Objective Robust Design Optimization," J. Mech. Des., vol. 126, no. 3, p. 395, 2004.

[54] Z. Kang and S. Bai, "On robust design optimization of truss structures with bounded uncertainties," Struct. Multidiscip. Optim., vol. 47, no. 5, pp. 699-714, Jan. 2013.

[55] D. D. Frey, "Application of Wavelets and Mahalanobis Distances to Robust Design of an Image Classification System," in ASI's 17th Annual Taguchi Methods Symposium, 1999.

[56] J. Zhu and K.-L. L. Ting, "Performance Distribution Analysis and Robust Design," J. Mech. Des., vol. 123, no. March 2001, p. 11, 2001.

[57] P. Lamberti and V. Tucci, "Interval approach to robust design," COMPEL Int. J. Comput. Math. Electr. Electron. Eng., vol. 26, no. 2, pp. 280-292, Apr. 2007.

[58] X. Du, A. Sudjianto, and W. Chen, "An Integrated Framework for Optimization Under Uncertainty Using Inverse Reliability Strategy," J. Mech. Des., vol. 126, no. 4, p. 562, 2004.

[59] X. Ren and S. Rahman, "Robust design optimization by polynomial dimensional decomposition," Struct. Multidiscip. Optim., vol. 48, no. 1, pp. 127-148, Mar. 2013.

[60] W. Chen and C. Yuan, "A probabilistic-based design model for achieving flexibility in design," J. Mech. Des., vol. 121, no. 1, p. 77, 1999.

[61] Y. Jin and B. Sendhoff, "Trade-off between performance and robustness: An evolutionary multiobjective approach," Evol. Multi-Criterion Optim., pp. 237-251, 2003.

[62] Q. Cheng, C. Xiao, G. Zhang, P. Gu, and L. Cai, "An analytical robust design optimization methodology based on axiomatic design principles," Qual. Reliab. Eng. Int., no. July 2013, 2013.

[63] K. N. Otto and E. K. Antonsson, "Design parameter selection in the presence of noise," Res. Eng. Des., vol. 6, no. 4, pp. 234-246, 1994.

[64] X. Du, "Toward Time-Dependent Robustness Metrics," J. Mech. Des., vol. 134, no. January 2012, p. 011004, 2012.

[65] W. Chen, T. W. Simpson, J. K. Allen, and F. Mistree, "Satisfying ranged sets of design requirements using design capability indices as metrics," Eng. Optim., vol. 31, no. 5, pp. 615-639, 1999.

[66] A. Heidari, Y.-J. Yoon, H. Son, and H.-J. Choi, "Simulation Based Design of Disk Resonator Biosensors Under Fabrication Uncertainty," J. Mech. Des., vol. 134, no. 4, p. 041005, 2012. 
ASME Journal of Mechanical Design

\section{Table Caption List}

Table $1 \quad$ Extraction statistic of the systematic literature review

Table $2 \quad$ Analysis scheme for robustness metrics

Table $3 \quad$ Classification scheme for robustness metrics

Table $4 \quad$ Nominal dimensions and material properties and variation data for the Toyota gas pedal input parameters

Table $5 \quad$ List of robustness metrics

Corresponding author: Göhler, Simon Moritz MD-16-1166 (Research paper) 41 of 42 
ASME Journal of Mechanical Design

Figure Captions List

Fig. 1 Robust Design framework

Fig. 2 Schematic diagram of the Toyota gas pedal [28]

Fig. 3 Size of feasible design space robustness measure (1D)

Fig. 4 Example for a feasible design space in 2D

Corresponding author: Göhler, Simon Moritz MD-16-1166 (Research paper) 42 of 42 